九州大学学術情報リポジトリ

Kyushu University Institutional Repository

\title{
Influence of offshore topography on the amplification of infragravity oscillations within a harbor
}

Gao, Junliang

School of Naval Architecture and Ocean Engineering, Jiangsu University of Science and Technology

Ji, Chunyan

School of Naval Architecture and Ocean Engineering, Jiangsu University of Science and Technology

Liu, Yingyi

Research Institute for Applied Mechanics, Kyushu University

Ma, Xiaojian

School of Naval Architecture and Ocean Engineering, Jiangsu University of Science and Technology

他

http://hdl. hand le. net/2324/4055201

出版情報: Applied 0cean Research. 65，pp.129-141，2017-04-14. Elsevier バージョン：

権利関係: Creative Commons Attribution NonCommercial NoDerivatives 4.0 International 
Influence of offshore topography on the amplification of infragravity oscillations within a harbor

$$
\text { Junliang Gao }{ }^{1,2,3 *} \text {, Chunyan } \mathrm{Ji}^{1} \text {, Yingyi Liu }{ }^{4}, \text { Xiaojian } \mathrm{Ma}^{1} \text {, Oleg Gaidai }{ }^{1}
$$

1 School of Naval Architecture and Ocean Engineering, Jiangsu University of Science and Technology, Zhenjiang 212003, China

2 Jiangsu Key Laboratory of Coast Ocean Resources Development and Environment Security, Hohai University, Nanjing 210098, China

3 State Key Laboratory of Coastal and Offshore Engineering, Dalian University of Technology, Dalian 116024, China

4 Research Institute for Applied Mechanics, Kyushu University, Kasuga, Fukuoka 816-8580, Japan

\section{Abstract}

The main purpose of this article is to systematically investigate the influence of offshore fringing reef topography on the infragravity-period harbor oscillations. The infragravity (IG) period oscillations inside an elongated harbor induced by normally-incident bichromatic wave groups are simulated using a fully nonlinear Boussinesq model, FUNWAVE 2.0. Based on an IG wave decomposition method, effects of plane reef-face slopes, reef-face profile shapes and the existence of reef ridge on bound and free IG waves and their relative components inside the harbor are comprehensively studied. For the given harbor and reef ridge, the range of the reef-face slopes and the various profile shapes studied in this paper, results show that the amplitude of the free IG waves inside the harbor increases with the increasing of the reef-face slope; while the bound IG waves inside the harbor seem insensitive to it. The effects of the profile shapes on the IG period waves inside the harbor are closely related to the width of the reef face. The existence of the reef ridge can relieve the bound IG waves to some extent when the incident short wave amplitudes are relatively large, while its effects on the free IG waves are negligible.

\section{Key words:}

Harbor oscillations; Resonance; Topography; Bound infragravity waves; Free infragravity waves; Wave groups; FUNWAVE 2.0 model

\footnotetext{
${ }^{*}$ Corresponding author. Tel.: 86-511-8444 8827, E-mail: gaojunliang880917@163.com (J. Gao).
} 


\section{Introduction}

In the real ocean, wind waves and swell waves always propagate in the form of wave groups. Via nonlinear wave-wave interactions, long waves with periods of 30 to $300 \mathrm{~s}$, also defined as infragravity (IG) waves, can be generated and propagate beneath the primary (short) wave groups. When the IG waves with frequencies close to those of resonating harbor modes come into a harbor entrance, they can be highly amplified into inner basins and cause large oscillations of the water surface [1-3]. By creating unacceptable vessel movements, harbor oscillations may interrupt the operation of docks and generate excessive mooring forces that may break mooring lines [4]. Besides the IG waves through nonlinear interactions of the primary waves, other external forces can also induce significant oscillations within a harbor, which include atmospheric pressure fluctuations [5], shear flows [6], tsunamis and impact waves induced by landslides or the failure of structures near the harbor $[7,8]$.

Although research efforts on harbor resonance began in the early 1950s [9], the majority of past studies have assumed that the water depth inside and outside the harbor is constant (e.g., [1-3, 10-13]), and the topographic influence on harbor oscillations has not been considered in these papers. In fact, the investigation of the influence of topography on harbor resonance started relatively late and few researchers focused on this problem. Using the method of matched asymptotic expansion, Liu [14] analytically examined the effects of water depth discontinuity near the harbor entrance on harbor oscillations. Panchang et al. [15] proposed an elliptic harbor wave model combining with a one-dimensional representation of the exterior bathymetry to consider exterior bathymetric effects on the wave field inside the harbor. Recently, based on analytical or numerical methods, the effects of various topographies inside the harbor on harbor oscillations were investigated by several researchers (e.g., [16-18]). Although different methods and bottom profiles inside the harbor were adopted in these works, consistent evidence of the influence of topographic variation on the wave conditions inside the harbor was found.

The vast majority of the world's coastlines, perhaps reaching up to $80 \%$, contain a broad class of submerged reef structures, which include tropical coral reefs, relic temperate limestone platforms and rocky coastal features [19]. Therefore, in the last few decades, wave interactions with fringing coral reefs have been one of the primary focuses of the offshore and nearshore hydrodynamics $[19,20]$. However, the existing literature on wave hydrodynamics over fringing 
reefs mainly focused on the problems such as wave setup/setdown, wave-generated flow, wave dissipation and energy evolution. Investigations on influences of fringing reefs on the wave fields inside the harbor are rare. In addition, based on field measurements in Two Rocks Marina in south-west Australia and numerical simulations of a Boussinesq model, Thotagamuwage and Pattiaratchi [21] found that during stormy sea conditions, offshore reefs can increase the IG wave energy over the offshore reefs by a factor of 8-10 compared to the IG wave energy at offshore, and the increased IG wave energy over the offshore reefs elevated the IG wave energy towards the nearshore and significantly enhanced the IG period oscillations inside the harbor. Therefore, considering remarkable impacts of fringing reefs on harbor oscillations and relatively few studies so far, more investigation efforts should be made to improve the knowledge on wave hydrodynamics related to fringing reefs.

The geometrical characteristics of fringing reefs are different from those of normal coastal beaches in many aspects. A typical fringing reef is characterized by a seaward sloping reef face and an inshore shallow reef flat extending towards the coastline, and reef ridges or similar configurations ("reef crest" or "reef rim" in some literature) have been frequently observed at the edges of coral reefs although the reef profile may vary from site to site [22]. To enhance the understanding of influences of fringing reefs on the IG period harbor oscillations, this paper systematically investigates how reef-face slopes, profile shapes and the existence of reef ridge affect the bound and free IG waves and their relative components inside the harbor. In this article, all simulations are based on the fully nonlinear Boussinesq model, FUNWAVE 2.0, which was proposed by Kirby et al. [23]. For simplification, the harbor is assumed to be long and narrow such that the free surface movement inside the harbor becomes one dimensional. The water depth inside the harbor is constant, and the incident waves are bichromatic with two slightly different frequencies. The analysis technique proposed by Dong et al. [11] is adopted to decompose the IG period components inside the harbor into bound and free IG waves.

It should be noted here that although considerable free IG waves can be generated by wave breaking over fringing reefs [21], which would dramatically change the IG wave fields and the relative components of bound and free IG waves inside the harbor, due to the following two reasons, wave breaking is not considered in the current study. Firstly, the wave breaking phenomenon when the incident waves from the open ocean propagate across fringing reefs does 
not always occur. Hardy and Young [24] conducted field experiments which obtained measurements of the attenuation and transformation of short gravity waves as they propagated across the windward edge of John Brewer Reef, located $70 \mathrm{~km}$ northeast of Townsville, Queensland, Australia. Water-level data were collected for over 3000 individual time series during a wide range of environmental conditions. They found that the wave energy on the reef flat was controlled by both incident wave energy and the water depth. At higher tide levels, wave breaking is nonexistent when the incident wave energy is relatively small; on the contrary, wave breaking mainly occurs at lower tide levels. Similar evidence for the existence of the nonbreaking wave condition over fringing reefs can also be found in Gourlay [25]. Therefore, the present study also has practical engineering and scientific significance although wave breaking over fringing reefs is not considered. Secondly, the current study can lay a good foundation for the further research in which wave breaking is considered. Specifically speaking, the investigation findings in this paper can be utilized to investigate similarities and differences with related phenomena when wave breaking is considered, which will help people to understand the IG wave hydrodynamics inside the harbor located near fringing reefs more comprehensively. Thus, the present study also has certain reference value for the further study in which wave breaking is considered.

The remainder of the paper is organized as follows: Section 2 describes the numerical model and the analysis technique. The applicability of the former over rapidly varying bathymetry will be verified by a set of numerical experiments. Section 3 presents the numerical experiment setup and the experimental wave parameters. Section 4 demonstrates the simulation results, which are explained in detail. Concluding remarks based on the results are given in Section 5.

\section{Numerical model and analysis technique}

\subsection{Numerical model}

\subsubsection{Model description}

All numerical experiments in this paper are performed using the well-known and widely implemented FUNWAVE 2.0 model [23], which uses the fully nonlinear Boussinesq wave model on curvilinear coordinates. The one-way wave maker theory proposed by Chawla and Kirby [26] is used to generate monochromatic or random waves. Sponge layers are placed at the boundaries of the domain to effectively absorb the energy of outgoing waves with various frequencies and directions. The capability of the model to predict wave propagation and transformation from 
deep to shallow water has been well validated by laboratory experiments $[23,27]$.

To verify the applicability of the FUNWAVE 2.0 model to simulate harbor oscillations with strong wave nonlinearity inside the harbor, Gao et al. [28] used the model to reproduce the physical experiments conducted by Rogers and Mei [29]. Gao et al. [28] compared the numerical results of the first three super harmonics with the experimental data of Rogers and Mei [29] for two elongated rectangular bays of different lengths. Overall agreement was observed between the measured data and the numerical results for all the three super harmonics. It was shown that the numerical model can also simulate strong nonlinear harbor oscillations accurately.

\subsubsection{Model validation for rapidly varying bathymetry}

Unlike coastal beaches, which normally have mild slopes, a typical fringing reef often includes a steep transition from the relatively deep to shallow waters. One of the major concerns with applying Boussinesq equation models to fringing reefs is the relatively steep reef-face the derivation process of Boussinesq equations.
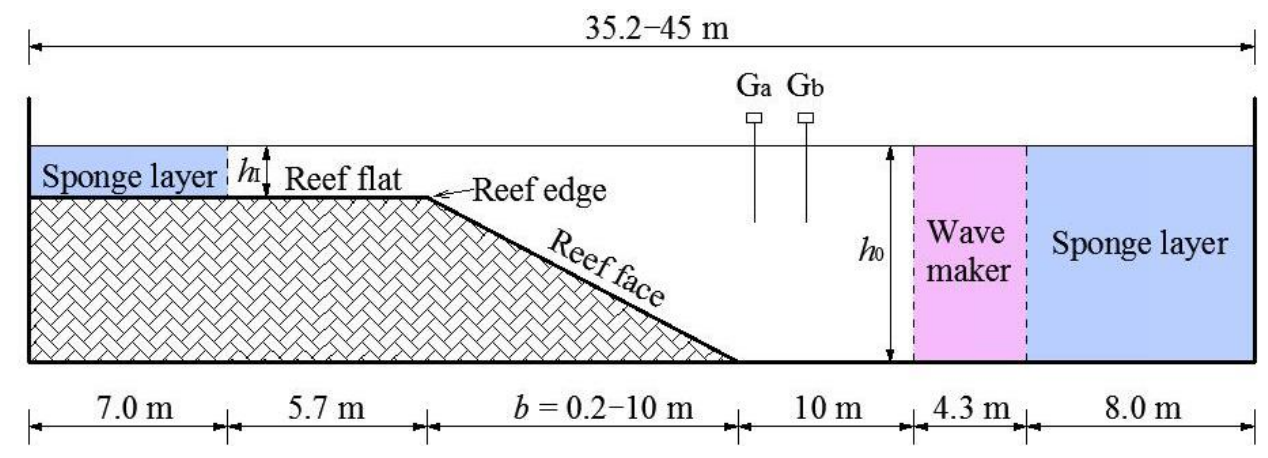

Fig. 1. Sketch of the numerical wave tank used in testing experiments (incident waves propagating from right to left)

To verify the ability of the FUNWAVE 2.0 model to deal with rapidly varying bathymetry, a train of monochromatic waves propagating over plane reef faces with different slopes are considered here. Booij [30] first investigated this problem to examine the accuracy of a mild-slope equation by comparing the predicted reflection coefficients with finite element method (FEM) solutions. Booij's FEM solution, however, covers the slope range steeper than about 1:3 and no data is provided for the milder slopes. Subsequently, Suh et al. [31] extended 
Booij's FEM solution to the milder slopes. Then, Madsen et al. [32] and Yao et al. [22] reproduced this problem to validate the capacity of their respective Boussinesq equation models. Fig. 1 shows the bottom profile for this problem, which consists of a plane slope connecting two constant-depth regions. The offshore water depth, $h_{0}$, is $0.6 \mathrm{~m}$; while the reef-flat water depth, $h_{\mathrm{I}}$, is set to $0.2 \mathrm{~m}$. A train of monochromatic waves with a period of $T=2.0 \mathrm{~s}$ are simulated. The width of the reef face, $b$, varies from $0.2 \mathrm{~m}$ to $10 \mathrm{~m}$, corresponding to the slope of $S=$ $\left(h_{0}-h_{\mathrm{I}}\right) / b=2.0-0.04$. Identical to Yao et al. [22], a grid size of $0.04 \mathrm{~m}$ and a time step of $0.01 \mathrm{~s}$ are adopted for all simulations. Two wave gauges, $G_{a}$ and $G_{b}$, are deployed to decompose the incident and reflected monochromatic waves. Their distances from the toe of reef face are $4.12 \mathrm{~m}$ and $4.36 \mathrm{~m}$, respectively. Sponge layers are placed at the left and right boundaries of the domain to effectively absorb the incident and reflected waves.

155

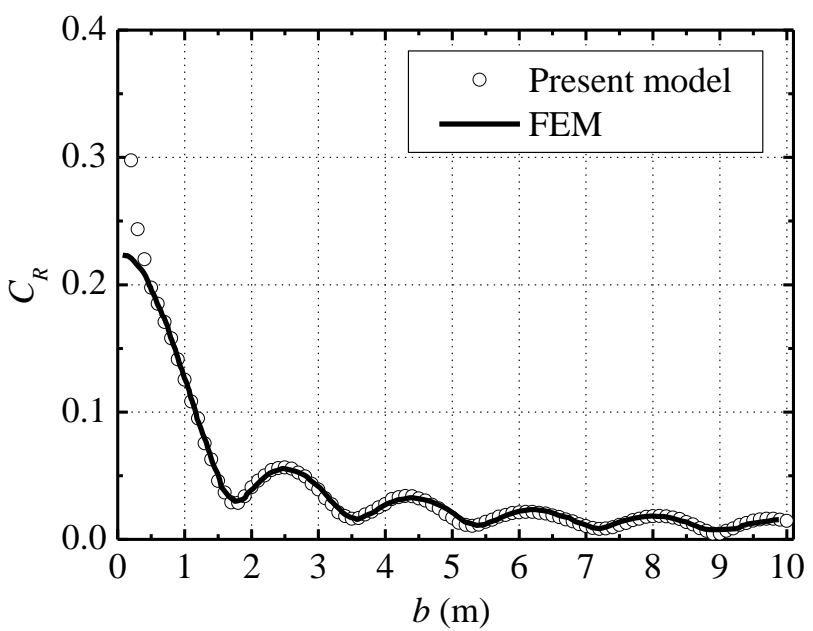

Fig. 2. Variation of the reflection coefficient, $C_{\mathrm{R}}$, with respect to the width of the reef face, $b$. Open circles: present model, solid line: FEM solution of Suh et al. [31].

Fig. 2 presents the comparison of the simulated reflection coefficients and the FEM solutions of Suh et al. [31]. It clearly demonstrates that the present numerical results are accurate up to the reef-face width of $b=0.5 \mathrm{~m}$, i.e., a slope of $S=0.8$, but obviously underestimate the reflection coefficients for very steep slopes. The fluctuation of reflection coefficient with $b$ is attributed to the trapping of the wave energy by reflection along the reef face [22].

2.2. Analysis technique

Identical to Gao et al. [12], the IG wave separation procedure proposed by Dong et al. [11] 
is adopted in this article to decompose the IG period components inside the harbor into bound and free IG waves. To facilitate the reader's understanding of this paper, the wave analysis technique is briefly described in this section.

Fig. 3 illustrates the sketch of the harbor studied in this paper and the arrangement of the wave gauges inside the harbor. The harbor has a length of $L=50.0 \mathrm{~m}$ and a width of $W=5.0 \mathrm{~m}$. There are 21 wave gauges $\left(\mathrm{G}_{01}-\mathrm{G}_{21}\right)$ deployed equidistantly with a spacing of $D=2.5 \mathrm{~m}$ along the center line of the harbor. The origin of the Cartesian coordinate system $(o, x, y, z)$ is placed at the still water level with $z$ measured upwards. The gauge $G_{01}$ is installed near the inner end of the harbor; the gauge $G_{21}$ is at the midpoint of the harbor entrance. The water depth inside the harbor is constant and equal to $h_{\mathrm{I}}=1.0 \mathrm{~m}$.

Fig. 3. Definition sketch of the harbor, the arrangement of the wave gauges and the coordinate system.

When the elongated harbor is subjected to incident bichromatic waves groups, primary waves, second-order bound and free IG waves all take the form of standing waves inside the harbor. Because of the fully reflecting vertical wall at the inner end of the harbor, an antinode exists at $x=0$ for all the standing wave components. Bowers [1] has formulated these standing wave components. Following his equations, the IG period component free-surface inside the harbor can be expressed analytically as follows:

$$
\eta_{\mathrm{L}}=\zeta_{\mathrm{b}} \cos \left[(2 \pi \Delta f) t-\alpha_{\mathrm{b}}\right] \cos (\Delta k x)+\zeta_{\mathrm{f}} \cos \left[(2 \pi \Delta f) t-\alpha_{\mathrm{f}}\right] \cos (\kappa x),
$$

where

$$
\begin{gathered}
\Delta f=\left|f_{1}-f_{2}\right|, \\
\Delta k=\left|k_{1}-k_{2}\right|
\end{gathered}
$$


and $\left(f_{1}, k_{1}\right)$ and $\left(f_{2}, k_{2}\right)$ denote the frequencies and wavenumbers of the primary waves and satisfy the linear dispersion relation:

$$
\left(2 \pi f_{i}\right)^{2}=g k \tanh \left(k_{i} h_{\mathrm{I}}\right) \quad(i=1,2) .
$$

The first and second terms on the right-hand-side of Eq. (1) represent the bound and free IG standing wave components, respectively. $\Delta f$ and $\Delta k$ denote the frequency and wavenumber of the bound IG waves. $\kappa$ denotes the wavenumber of the free IG waves, and $(\kappa, \Delta f)$ also satisfy the linear dispersion relation. $\zeta_{\mathrm{b}}$ and $\zeta_{\mathrm{f}}$ denote the amplitudes of the envelop of the bound and free IG standing waves, respectively, and $\alpha_{\mathrm{b}}$ and $\alpha_{\mathrm{f}}$ denote the initial phases of the bound and free IG waves, respectively. The gravitational acceleration is denoted by $g$. Bowers [1] noted that the second-order bound sub-harmonics contain not only the ( $\Delta f, \Delta k)$ component but also the $\left(\Delta f, k_{1}+k_{2}\right)$ component. However, calculations based on the equations in Bowers [1] demonstrate that the $(\Delta f, \Delta k)$ component is approximately $8.62 \times 10^{3}$ times the $\left(\Delta f, k_{1}+k_{2}\right)$ component in the range of our simulations (this will be described in detail in Section 3). Therefore, the $\left(\Delta f, k_{1}+k_{2}\right)$ component is neglected, just as it was in Bowers [1].

After some trigonometric manipulations, the squared amplitude of the IG period component along the central line can be expressed as follows:

$$
A_{\mathrm{IG}}(x)^{2}=a \varphi_{0}(x)+b \varphi_{1}(x)+c \varphi_{2}(x),
$$

where

$$
\begin{aligned}
& a=\zeta_{\mathrm{b}}{ }^{2}, b=\zeta_{\mathrm{f}}{ }^{2}, c=2 \zeta_{\mathrm{b}} \zeta_{\mathrm{f}} \cos \left(\alpha_{\mathrm{b}}-\alpha_{\mathrm{f}}\right), \\
& \varphi_{0}(x)=\cos ^{2}(\Delta k x), \varphi_{1}(x)=\cos ^{2}(\kappa x), \varphi_{2}(x)=\cos (\Delta k x) \cos (\kappa x) .
\end{aligned}
$$

The amplitudes of the IG period component at every gauge location, $A_{\mathrm{IG}}\left(x_{i}\right)(i=1,2, \ldots, 21)$, can be obtained using the discrete Fourier transform for the free surface signals. $x_{i}$ denotes the abscissa value of each wave gauge. Because $\varphi_{0}(x), \varphi_{1}(x)$ and $\varphi_{2}(x)$ are linearly independent, the unknown variables $a, b$ and $c$ can be obtained using the least squares method. Then the values of $\zeta_{\mathrm{b}}, \zeta_{\mathrm{f}}$ and $\left|\alpha_{\mathrm{b}}-\alpha_{\mathrm{f}}\right|$ will be obtained naturally. The capacity of IG wave separation procedure to accurately decompose the bound and free IG waves inside the harbor under different resonant modes have been fully verified in Dong et al. [11] and Gao et al. [12].

It should be noted that Ruessink [33] adopted another analysis technique, that is, the bispectral analysis, to separate the bound and free IG waves in the nearshore zone under breaking and nonbreaking conditions. However, aiming at the incident wave conditions (i.e., bichromatic wave groups) and the elongated harbor with constant depth studied in this paper, the IG wave 
separation procedure proposed by Dong et al. [11] seems more direct and more simpler compared with the bispectral analysis. Besides, based on the feature that both the bound and free IG waves take the form of standing waves inside the harbor, the method of Dong et al. [11] utilizes the free-surface signals at all wave gauges inside the harbor to separate these two IG wave components. In this sense, the separation results obtained by the method of Dong et al. [11] represent the magnitudes of the bound and free IG waves in the whole harbor domain. On the contrary, the bispectral technique only analyzes the free-surface signals at a certain wave gauge. Hence the analysis results gained by it are only valid fort that wave gauge, and hardly reflect the magnitudes of the bound and free IG waves in the whole harbor domain. For these reasons, the IG wave separation procedure proposed by Dong et al. [11] is adopted in current study.

\section{Numerical experimental setup}
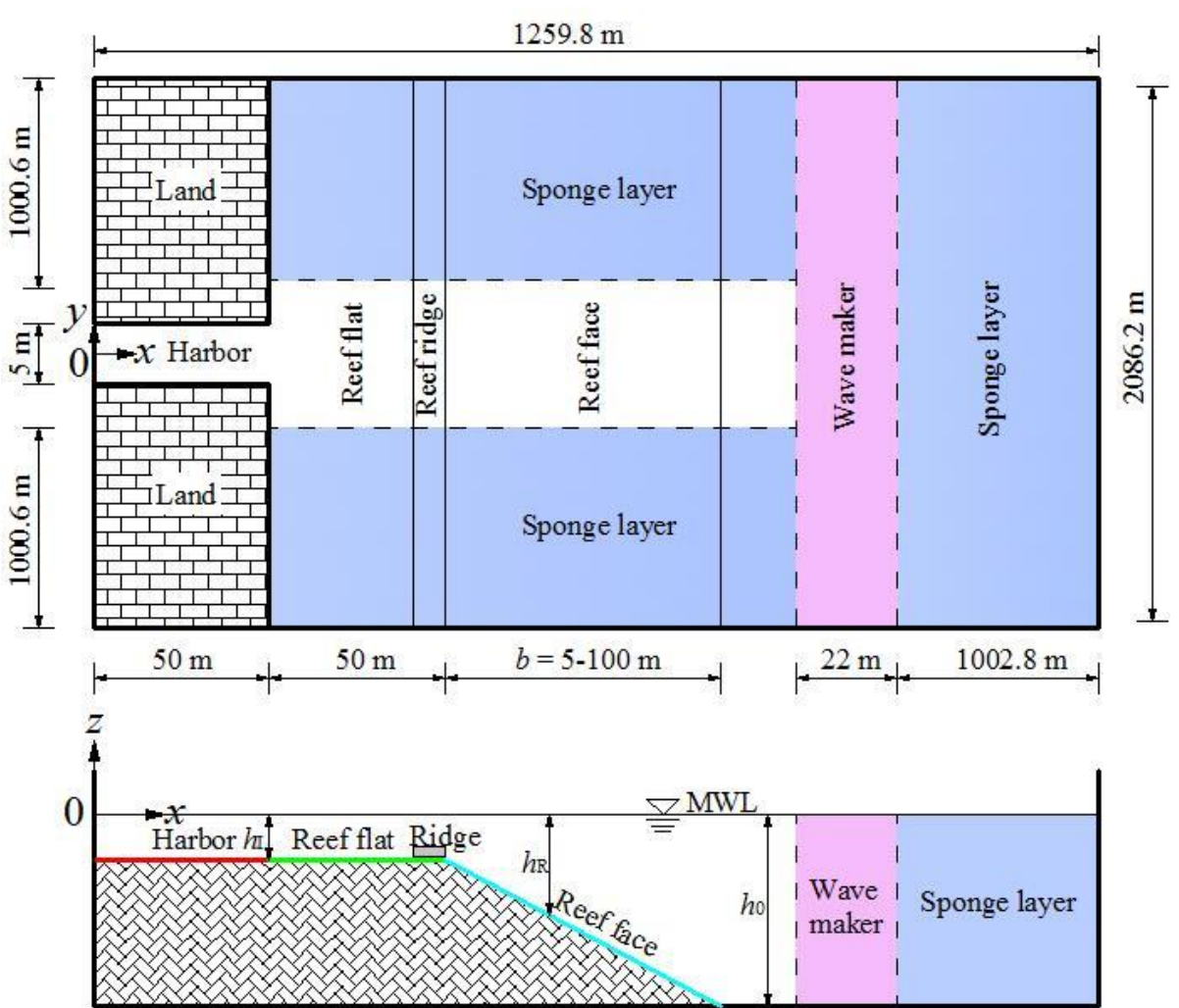

Fig. 4. Sketch of the numerical wave flume. Upper panel: top view; lower panel: longitudinal section at $y=0$ (taking the reef face with the plane slope for example). Since the wave tank is symmetric with respect to the $x$-axis, only a half-domain (i.e. $y \geq 0$ ) is used for computations.

Fig. 4 illustrates the numerical wave tank used in the numerical experiments. Dimensions of the numerical wave tank are $1259.8 \mathrm{~m} \times 2086.2 \mathrm{~m}$. All the boundaries are set to be fully 
reflective. As has been mentioned above, the harbor has a length of $50.0 \mathrm{~m}$ and a width of $5.0 \mathrm{~m}$. Twenty-one wave gauges $\left(\mathrm{G}_{01}-\mathrm{G}_{21}\right)$ are arranged equidistantly along the center line of the harbor with a spacing of $2.5 \mathrm{~m}$ (refer to Fig. 3). The length of the reef flat located outside the harbor is set to $50.0 \mathrm{~m}$. To investigate effects of the reef-face slope on the IG waves inside the harbor, the width of the reef face, $b$, varies gradually from $5 \mathrm{~m}$ to $100 \mathrm{~m}$. The still water depth both inside the harbor and over the reef flat is constant, equal to $h_{\mathrm{I}}=1.0 \mathrm{~m}$, while the water depth over the open ocean is set to $h_{0}=5.0 \mathrm{~m}$. Using the linear analytical solution for the resonance of an elongated rectangular harbor in the absence of dissipation [34], the natural frequencies of the lowest five modes of the harbor illustrated in Figs. 3 and 4 are calculated and listed in Table 1. In this paper, only the lowest resonant mode induced by bichromatic wave groups is investigated. In all the numerical experiments, the incident primary wave components have the frequencies of $f_{1}=0.25 \mathrm{~Hz}$ and $f_{2}=0.264 \mathrm{~Hz}$, which makes the beat frequency, $\Delta f=\left|f_{1}-f_{2}\right|$, correspond to the lowest resonant mode. In this case, the relative water depth $h_{0} / l_{0}$ is equal to 0.21 ( $l_{0}$ denotes the average deep-water wavelength of the bichromatic primary waves); within this range, the FUNWAVE 2.0 model can be used to simulate the wave propagation and transformation accurately [23]. For the incident primary wave amplitudes, the following four different conditions are considered: (1) $a_{1}=a_{2}=0.01 \mathrm{~m},(2) a_{1}=a_{2}=0.02 \mathrm{~m},(3) a_{1}=a_{2}=0.04 \mathrm{~m}$ and (4) $a_{1}=0.04 \mathrm{~m}$ and $a_{2}=0.01 \mathrm{~m} . a_{1}$ and $a_{1}$ denote the amplitudes of the incident primary wave $f_{1}$ and $f_{2}$ components, respectively. The incident bichromatic wave groups for the first three conditions are fully modulated with the modulation rate of $\delta=a_{2} / a_{1}=1.0$, while for the last condition, the incident wave groups are weakly modulated with $\delta=0.25$. Due to different water depths inside the harbor and at the open ocean, based on the linear dispersion relation, the wavelengths of the free IG waves at these two regions are $223.7 \mathrm{~m}$ and $499.9 \mathrm{~m}$, respectively; while the wavelengths of the bound IG waves are 195.5 $\mathrm{m}$ and $255.8 \mathrm{~m}$, respectively. Meanwhile, to investigate the influence of the existence of reef ridge on the IG waves inside the harbor, two types of idealized fringing-reef profiles are considered: (1) a fringing reef without a ridge and (2) a fringing reef with an idealized ridge. For the latter, a rectangular box (2086.2 $\mathrm{m}$ long, $6.0 \mathrm{~m}$ wide and $0.3 \mathrm{~m}$ high) is placed on the reef flat with its front face aligned to the reef edge to simulate an idealized ridge. To ensure the numerical stability, both seaside and lee side vertical faces of the ridge are modified to a slope of $S=0.6$ in the numerical simulations. To effectively absorb the energy of the radiated and reflected waves, 
sponge layers are installed at the right, bottom and upper boundaries of the wave tank, and their widths are set to be slightly larger than 2.0 times the wavelength of the free IG waves at the open ocean. To save the computational cost, only half of the domain (i.e. $y \geq 0$ ) is used as the computational domain for simulations based on the geometrical symmetry with respect to the $x$-axis. Because the FUNWAVE 2.0 model is discretized using curvilinear grids, different grid sizes can be adopted. In the $x$-direction, the grid sizes $\Delta x$ are all equal to $0.5 \mathrm{~m}$ both inside and outside the harbor except in the sponge layer at the right boundary. To reduce the large computational cost associated with the very thick sponge layer, the grid sizes $\Delta x$ in the sponge layer increase gradually from $0.5 \mathrm{~m}$ to $18.7 \mathrm{~m}$. While in the $y$-direction, the grid sizes $\Delta y$ increase gradually from $0.5 \mathrm{~m}$ inside the harbor to $19.9 \mathrm{~m}$ outside the harbor. To obtain a good convergence rate, the Courant number $C r=\sqrt{g h} \Delta t / \min (\Delta x, \Delta y)$ should be less than 0.5 . Therefore, a time step of $\Delta t=0.025 \mathrm{~s}$ is used in all simulations, and the total simulation time is

Table 1. Linear analytical solution [34]: natural frequencies, $f(\mathrm{~Hz})$, and amplification factors, $R(f)$, of the first five resonant modes of the harbor shown in Figs. 3 and 4.

\begin{tabular}{cccccc}
\hline & \multicolumn{2}{c}{ Resonant mode } & & & \\
\cline { 2 - 6 } & I & II & III & IV & V \\
\hline$f$ & 0.014 & 0.043 & 0.073 & 0.103 & 0.133 \\
$\mathrm{R}(f)$ & 14.35 & 4.83 & 2.98 & 2.21 & 1.77 \\
\hline
\end{tabular}

To study effects of different bottom profiles inside the harbor on transient harbor oscillations induced by solitary waves, Gao et al. [28] considered three types of bottom profiles, that is, a plane slope bottom, an arc-tangent-type bottom and a hyperbolic-cosine-type bottom. Inspired by Gao et al. [28], these three types of bottom profiles are also adopted in this paper to mimic different types of reef-face profiles. The still water depth over the reef face is thus given by

$$
h_{\mathrm{R}}(x)= \begin{cases}h_{\mathrm{I}}+S(x-100) & \text { Plane slope bottom } \\ h_{\mathrm{I}}+\alpha \operatorname{atan}[\beta(x-100)] & \text { Arc-tangent-type bottom } \\ h_{\mathrm{I}} \cosh ^{\kappa}[\mu(x-100)] & \text { Hyperbolic-cosine-type bottom }\end{cases}
$$

The symbols $S, \alpha, \beta, \kappa$ and $\mu$ are geometrical parameters determining the bottom profile over the 
reef face, which satisfy the following relationships:

$$
\begin{gathered}
S=\frac{h_{0}-h_{\mathrm{I}}}{b}, \\
\beta=\frac{1}{b} \tan \left(\frac{h_{0}-h_{\mathrm{I}}}{\alpha}\right),
\end{gathered}
$$

and

$$
\mu=\frac{1}{b} \operatorname{acosh}\left[\left(\frac{h_{0}}{h_{\mathrm{I}}}\right)^{1 / \kappa}\right] .
$$

It should be stressed here that for the reef face with plane slope, corresponding to the variation range of $b=5-100 \mathrm{~m}$, the slope $S$ varies gradually from 0.8 to 0.04 ; in this range, the reflection effect of the reef face can be accurately simulated by the FUNWAVE 2.0 model (refer to Section 2.1.2). While for both the arc-tangent-type and hyperbolic-cosine-type bottom profiles, only the cases when $b=50 \mathrm{~m}$ and $100 \mathrm{~m}$ are simulated. Table 2 presents the geometric parameters of the various bottom profiles over the reef face used in all the numerical experiments. The mean water depth over the reef face, $\bar{h}_{\mathrm{R}}$, can be calculated using the following formula:

$$
\bar{h}_{\mathrm{R}}=\frac{1}{b} \int_{100}^{100+b} h_{\mathrm{R}}(x) d x
$$

\begin{tabular}{|c|c|c|}
\hline Topography & \multicolumn{2}{|c|}{ Geometrical parameters } \\
\hline Plane & \multicolumn{2}{|c|}{$b=5 \mathrm{~m}-100 \mathrm{~m}, S=0.80-0.04, \bar{h}_{\mathrm{R}}=3.00 \mathrm{~m}$} \\
\hline \multirow{4}{*}{ Arc-tangent-type } & \multirow{2}{*}{$b=50 \mathrm{~m}$} & $\alpha=2.7 \mathrm{~m}, \quad \bar{h}_{\mathrm{R}}=4.42 \mathrm{~m}$ \\
\hline & & $\alpha=3.3 \mathrm{~m}, \quad \bar{h}_{\mathrm{R}}=3.70 \mathrm{~m}$ \\
\hline & \multirow{2}{*}{$b=100 \mathrm{~m}$} & $\alpha=2.7 \mathrm{~m}, \quad \bar{h}_{\mathrm{R}}=4.42 \mathrm{~m}$ \\
\hline & & $\alpha=3.3 \mathrm{~m}, \quad \bar{h}_{\mathrm{R}}=3.70 \mathrm{~m}$ \\
\hline \multirow{4}{*}{ Hyperbolic-cosine-type } & \multirow{2}{*}{$b=50 \mathrm{~m}$} & $\kappa=0.003, \quad \bar{h}_{\mathrm{R}}=2.48 \mathrm{~m}$ \\
\hline & & $\kappa=50, \quad \bar{h}_{\mathrm{R}}=1.94 \mathrm{~m}$ \\
\hline & \multirow{2}{*}{$b=100 \mathrm{~m}$} & $\kappa=0.003, \bar{h}_{\mathrm{R}}=2.48 \mathrm{~m}$ \\
\hline & & $\kappa=50, \quad \bar{h}_{\mathrm{R}}=1.94 \mathrm{~m}$ \\
\hline
\end{tabular}

308

Table 2. Geometric parameters of various reef-face profiles in all the numerical experiments 


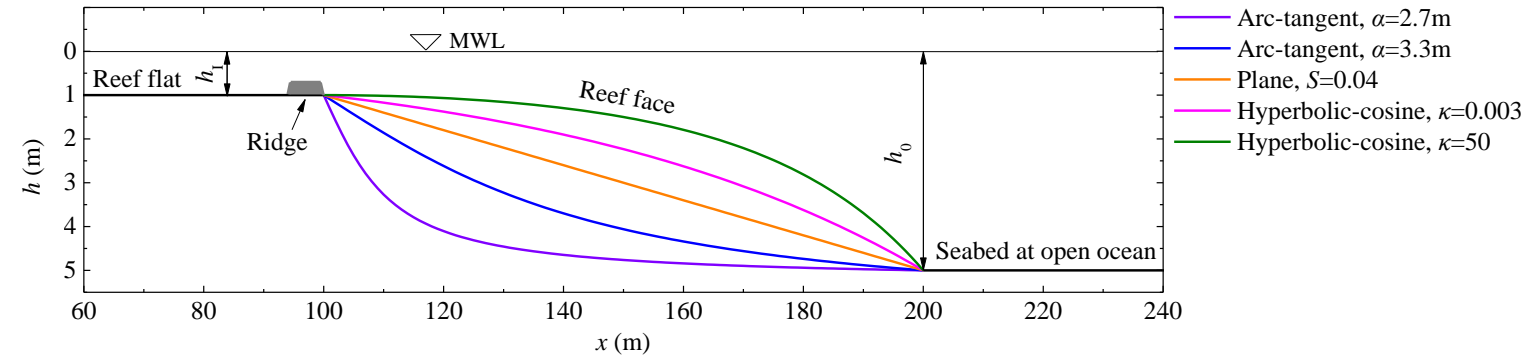

Fig. 5. Comparison of various reef-face profiles when the reef-face width, $b$, is equal to $100 \mathrm{~m}$

To visually display the shape differences of the topographies listed in Table 2, Fig. 5 demonstrates the comparison of various reef-face profiles when the reef-face width, $b$, equals $100 \mathrm{~m}$. For the two arc-tangent-type bottom profiles, due to the variation of $\alpha$, the mean water depths over the reef face are different; the values of $\alpha=2.7 \mathrm{~m}$ and $3.3 \mathrm{~m}$ correspond to the mean water depths of $\bar{h}_{\mathrm{R}}=4.42 \mathrm{~m}$ and $3.70 \mathrm{~m}$, respectively. Similarly, for the two hyperbolic-cosine-type bottom profiles, the mean water depths over the reef face are different due to different values of $\kappa$; the values of $\kappa=0.003$ and 50 correspond to the mean water depths of $\bar{h}_{\mathrm{R}}=2.48 \mathrm{~m}$ and $1.94 \mathrm{~m}$, respectively. For the plane slope bottom, the mean water depth over the reef face is $\bar{h}_{\mathrm{R}}=3.00 \mathrm{~m}$, which falls between those of the arc-tangent-type bottom with $\alpha=3.3$ $\mathrm{m}$ and the hyperbolic-cosine-type bottom with $\kappa=0.003$. For the reef face with the width of $b=50$ $\mathrm{m}$, the topographies for the various bottom profiles listed in Table 1 are identical to those shown in this figure except that the reef-face width is halved.

\section{Results and discussion}

\subsection{Time series and spectral analysis}

Time series and corresponding wavelet spectra of the wave elevations at gauge $G_{01}$ for different incident primary wave amplitudes under the conditions of $b=100 \mathrm{~m}$, plane reef face and no reef ridge are illustrated in Figs. 6 and 7, respectively. Note that in Fig. 6, the time series of the wave elevations at gauge $\mathrm{G}_{01}$ are normalized by the average incident primary wave amplitudes, $a=\left(a_{1} a_{2}\right)^{1 / 2}$. Fig. 6 shows that the free water surface inside the harbor is calm at the initial period of time. The incident primary waves reach the position of gauge $\mathrm{G}_{01}$ at about $60 \mathrm{~s}$ for all the four cases. Via the wavelet spectra shown in Fig. 7, the wave energy variation with respect to the frequency and the time can be visually illustrated. The energy of the primary wave 

steady until the end of the simulation. However, more time is needed for the IG period components to attain the quasi-steady state from the initial response phase. For both the four cases, the IG period components reach the quasi-steady state at about $t=350 \mathrm{~s}$. In this article, only the quasi-steady processes are investigated in all simulations.

341
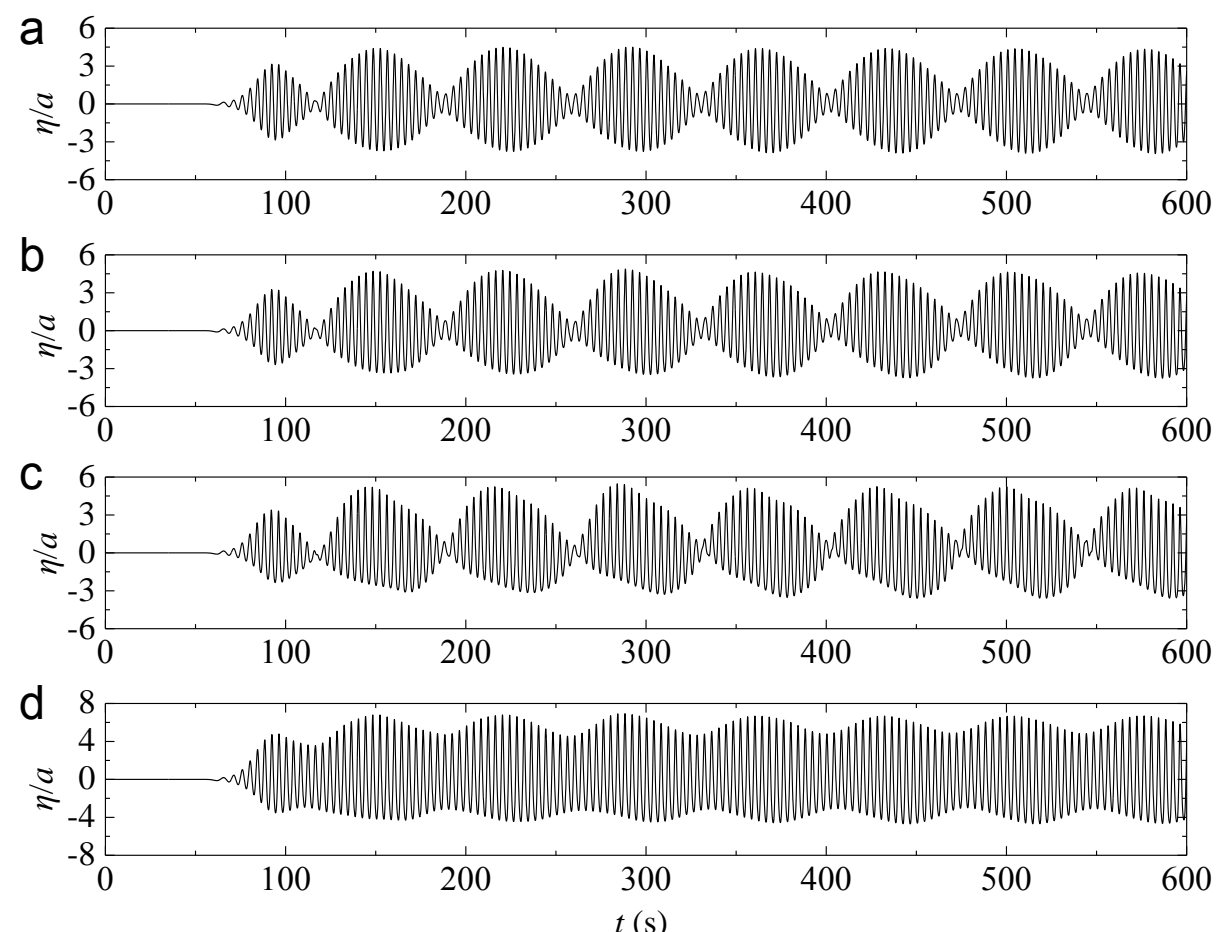

Fig. 6. Time series of the wave elevations at gauge $\mathrm{G}_{01}$ for (a) $a_{1}=a_{2}=0.01 \mathrm{~m}$, (b) $a_{1}=a_{2}=0.02 \mathrm{~m}$, (c) $a_{1}=a_{2}=0.04 \mathrm{~m}$ and (d) $a_{1}=0.04 \mathrm{~m}$ and $a_{2}=0.01 \mathrm{~m}$ under the conditions of $b=100 \mathrm{~m}$, plane reef face and no reef ridge, in which $a=\left(a_{1} a_{2}\right)^{1 / 2}$. 


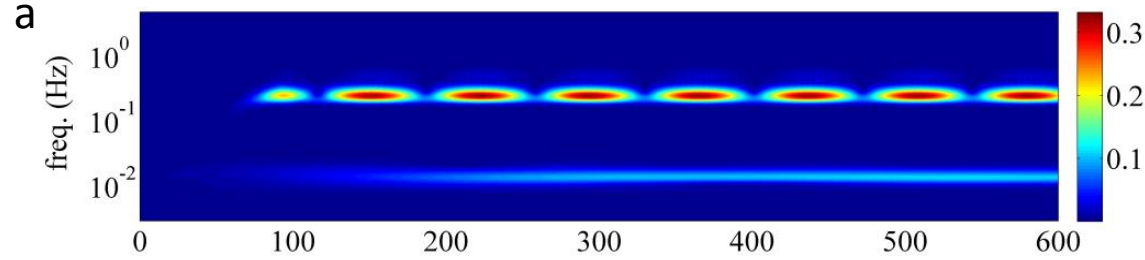

357

b
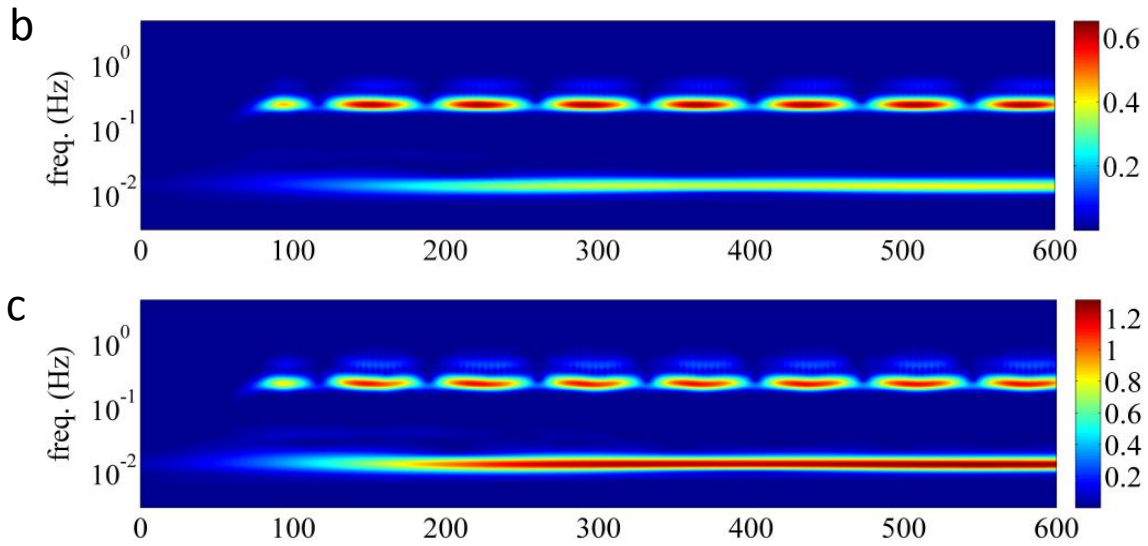

d

369

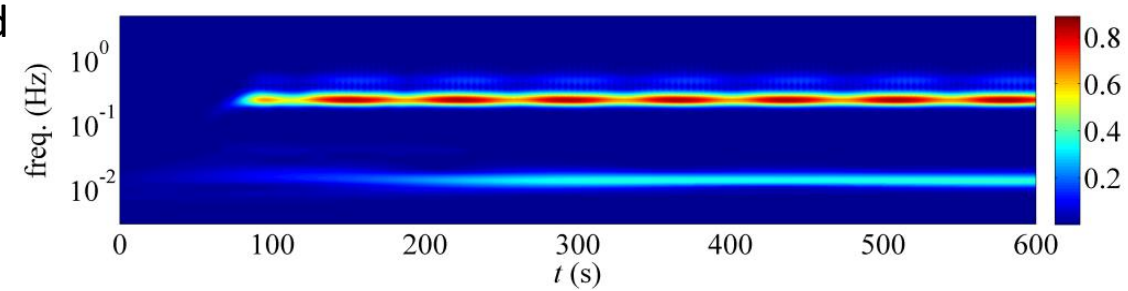

Fig. 7. Wavelet spectra at gauge $\mathrm{G}_{01}$ for (a) $a_{1}=a_{2}=0.01 \mathrm{~m}$, (b) $a_{1}=a_{2}=0.02 \mathrm{~m}$, (c) $a_{1}=a_{2}=0.04 \mathrm{~m}$ and (d) $a_{1}=0.04 \mathrm{~m}$ and $a_{2}=0.01 \mathrm{~m}$ under the conditions of $b=100 \mathrm{~m}$, plane reef face and no reef

371

a

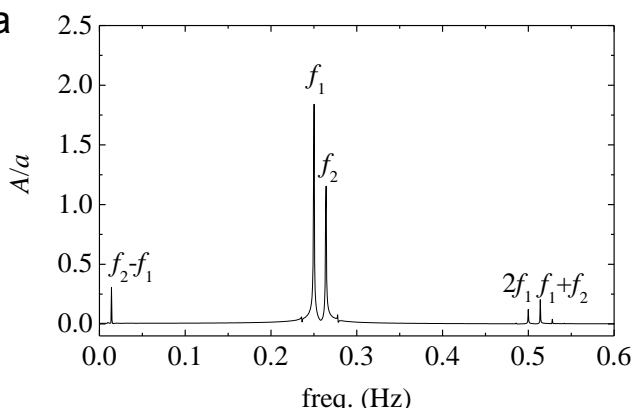

C

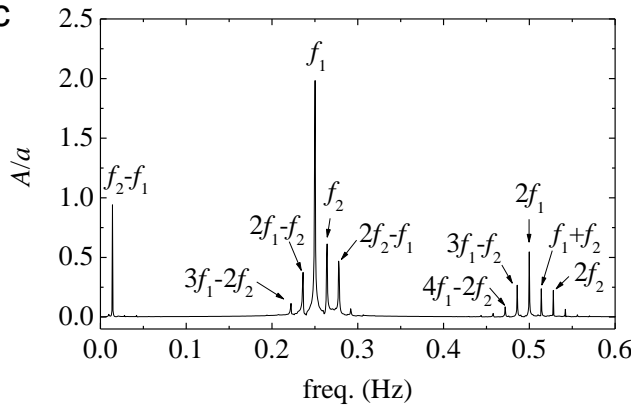

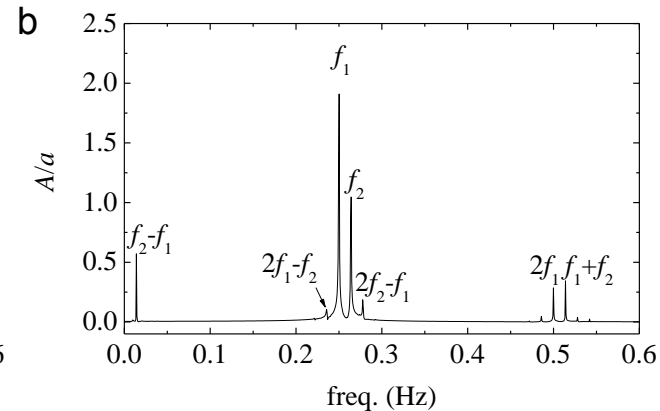

d

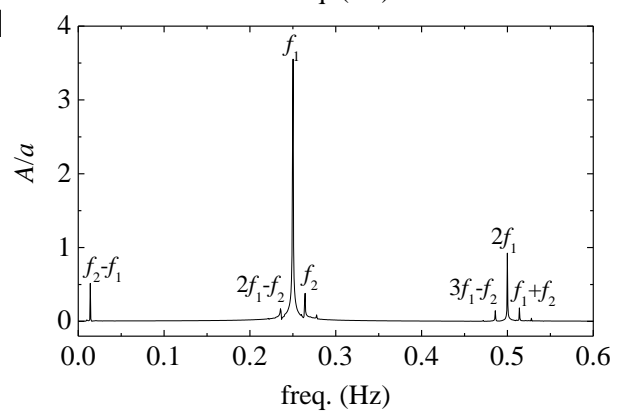

Fig. 8. Amplitude spectra at gauge $\mathrm{G}_{01}$ for (a) $a_{1}=a_{2}=0.01 \mathrm{~m}$, (b) $a_{1}=a_{2}=0.02 \mathrm{~m}$, (c) $a_{1}=a_{2}=0.04 \mathrm{~m}$ 

ridge.

During each run, data are recorded from all wave gauges simultaneously at a sampling time of $0.025 \mathrm{~s}$, yielding 80,000 data points per gauge. After discarding the first 14,464 data points from the beginning to eliminate the effects of the initial response phase, the remaining $2^{16}$ data points are analyzed by using a standard FFT (Fast Fourier Transform) package. Fig. 8 demonstrates the amplitude spectra at gauge $G_{01}$ for the four cases shown in Figs. 6 and 7. For the case with $a_{1}=a_{2}=0.01 \mathrm{~m}$ (Fig. $8 \mathrm{a}$ ), due to the smallest incident primary wave amplitudes, the wave nonlinearity in this case is weaker than that in the other three cases. In addition to the primary wave $f_{1}$ and $f_{2}$ components, only the second-order $f_{2}-f_{1}, 2 f_{1}$ and $f_{1}+f_{2}$ wave components are apparent in the amplitude spectrum. As the incident primary wave amplitudes increase, the nonlinear energy transfers between the primary waves and the high-order wave components become more intense and more complicated. For the two cases shown in Fig. 8b and d, which have the same average incident primary wave amplitude of $a=\left(a_{1} a_{2}\right)^{1 / 2}=0.02 \mathrm{~m}$, the third-order wave components, $2 f_{1}-f_{2}$ and $2 f_{2}-f_{1}$, and the fourth-order wave component, $3 f_{1}-f_{2}$, further appear in the two amplitude spectra. For the case with $a_{1}=a_{2}=0.04 \mathrm{~m}$ (Fig. 8c), owing to the largest incident primary wave amplitudes, more second- and higher-order wave components appear, and the magnitudes of the high-order wave components become more remarkable. The second-order super-harmonic component, $2 f_{1}$, has almost the same amplitude with the primary wave $f_{2}$ component, and the amplitude of the second-order sub-harmonic component, $f_{2}-f_{1}$, even exceeds that of the $f_{2}$ component. 
Without ridge
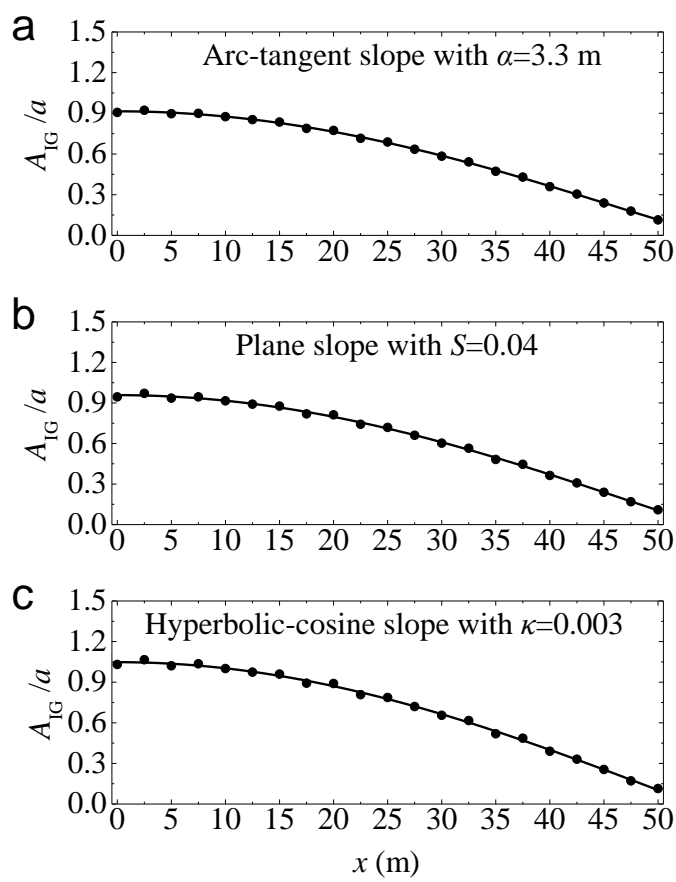

With ridge
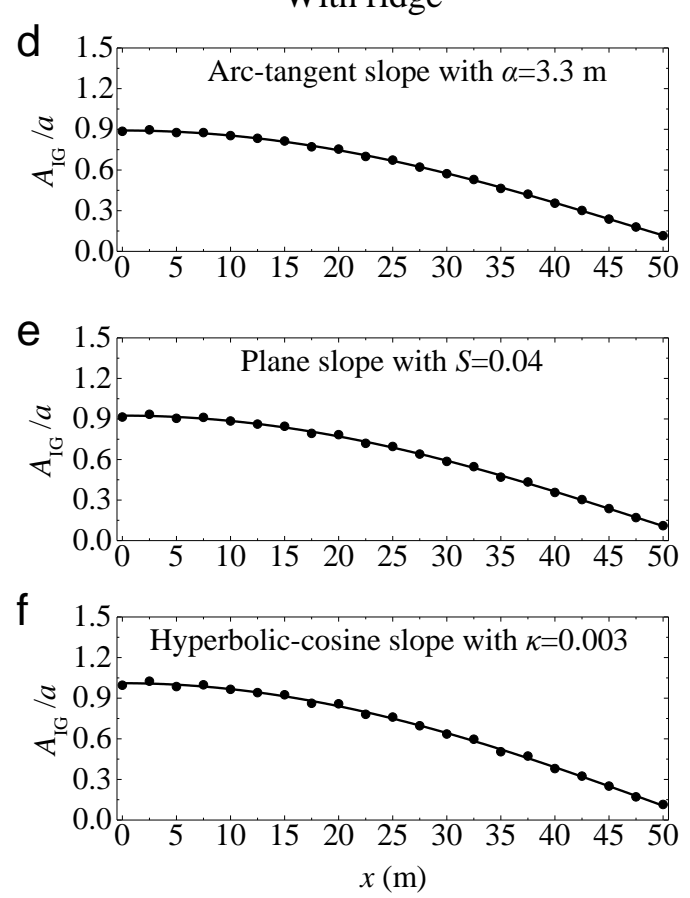

Fig. 9. Amplitudes of the IG period components (dots) at all wave gauges and their fitted envelopes (solid lines) obtained using the wave analysis technique for different reef-face profiles under the conditions of $b=100 \mathrm{~m}$ and $a_{1}=a_{2}=0.04 \mathrm{~m}$. (a) - (c) correspond to the cases without the reef ridge, and (d)-(f) correspond to the cases with the ridge.

Using the IG wave separation procedure described in Section 2.2, the bound and free IG standing wave components inside the harbor are decomposed in all the numerical experiments. Fig. 9 illustrates the amplitudes of the IG period components in all wave gauges and their fitted envelopes obtained using the separation procedure for different reef-face profiles under the conditions of $b=100 \mathrm{~m}$ and $a_{1}=a_{2}=0.04 \mathrm{~m}$. It is shown that the amplitudes of the IG period components at all wave gauges are very close to their fitted envelopes in all the six cases, which indicates that the separating amplitudes of the bound and free IG wave components obtained using the IG wave analysis technique are accurate and reliable. Table 3 presents the separation results of the six cases, in which $\zeta_{\mathrm{b}}$ and $\zeta_{\mathrm{f}}$ denote the amplitudes of the bound and free IG standing waves, respectively, and $\alpha_{\mathrm{b}}$ and $\alpha_{\mathrm{f}}$ denote their respective initial phases. For the six cases, although the values of $A_{\mathrm{IG}}, \zeta_{\mathrm{b}}$ and $\zeta_{\mathrm{f}}$ are different from each other, the values of $\zeta_{\mathrm{b}} / \zeta_{\mathrm{f}}$ are all 

those of the free IG waves inside the harbor.

Table 3. The separation results of the bound and free IG wave components for the six cases shown in Fig. 9.

\begin{tabular}{ccccc}
\hline Case & $\zeta_{\mathrm{b}}(\mathrm{m})$ & $\zeta_{\mathrm{f}}(\mathrm{m})$ & $\left|\alpha_{\mathrm{b}}-\alpha_{\mathrm{f}}\right|\left(^{\mathrm{o}}\right)$ & $\zeta_{\mathrm{b}} / \zeta_{\mathrm{f}}(\%)$ \\
\hline (a) & $1.33 \times 10^{-2}$ & $2.91 \times 10^{-2}$ & 66.2 & 45.8 \\
(b) & $1.39 \times 10^{-2}$ & $2.75 \times 10^{-2}$ & 47.3 & 50.6 \\
(c) & $1.43 \times 10^{-2}$ & $2.79 \times 10^{-2}$ & 16.1 & 51.4 \\
(d) & $1.20 \times 10^{-2}$ & $2.94 \times 10^{-2}$ & 68.5 & 40.9 \\
(e) & $1.26 \times 10^{-2}$ & $2.78 \times 10^{-2}$ & 51.7 & 45.4 \\
(f) & $1.34 \times 10^{-2}$ & $2.81 \times 10^{-2}$ & 28.2 & 47.4 \\
\hline
\end{tabular}

For the reef faces with different plane slopes, the variations of the separating amplitudes of the bound and free IG standing waves with respect to the slope coefficient, $S^{-1}$, under the conditions of different incident primary wave amplitudes are illustrated in Fig. 10. It is shown that for all the four incident primary wave amplitudes considered in this paper, the reef-face slope has a remarkable effect on the free IG waves inside the harbor; the amplitude of the free IG waves increases gradually with the increasing of the reef-face slope, $S$. However, the bound IG waves inside the harbor seem insensitive to the variation of the reef-face slope. Besides, it also can be seen that for all the cases shown in this figure, the amplitudes of the free IG waves are always larger than those of the bound IG waves inside the harbor, which agrees with the findings in Dong et al. [11] and Gao et al. [12]. It can be attributed to that the free IG waves inside the harbor correspond to the lowest resonant modes and are remarkably amplified. Fig. 11 demonstrates the variation of the amplitude ratio, $\zeta_{\mathrm{b}} / \zeta_{\mathrm{f}}$, with respect to the slope coefficient, $S^{-1}$, for different incident primary wave amplitudes. It can be seen that in general, the amplitude ratio, $\zeta_{\mathrm{b}} / \zeta_{\mathrm{f}}$, always decreases with the increasing of the reef-face slope, $S$, regardless of the incident primary wave amplitudes, the modulation rates of the wave groups and whether the reef ridge exists or not. 
Without ridge
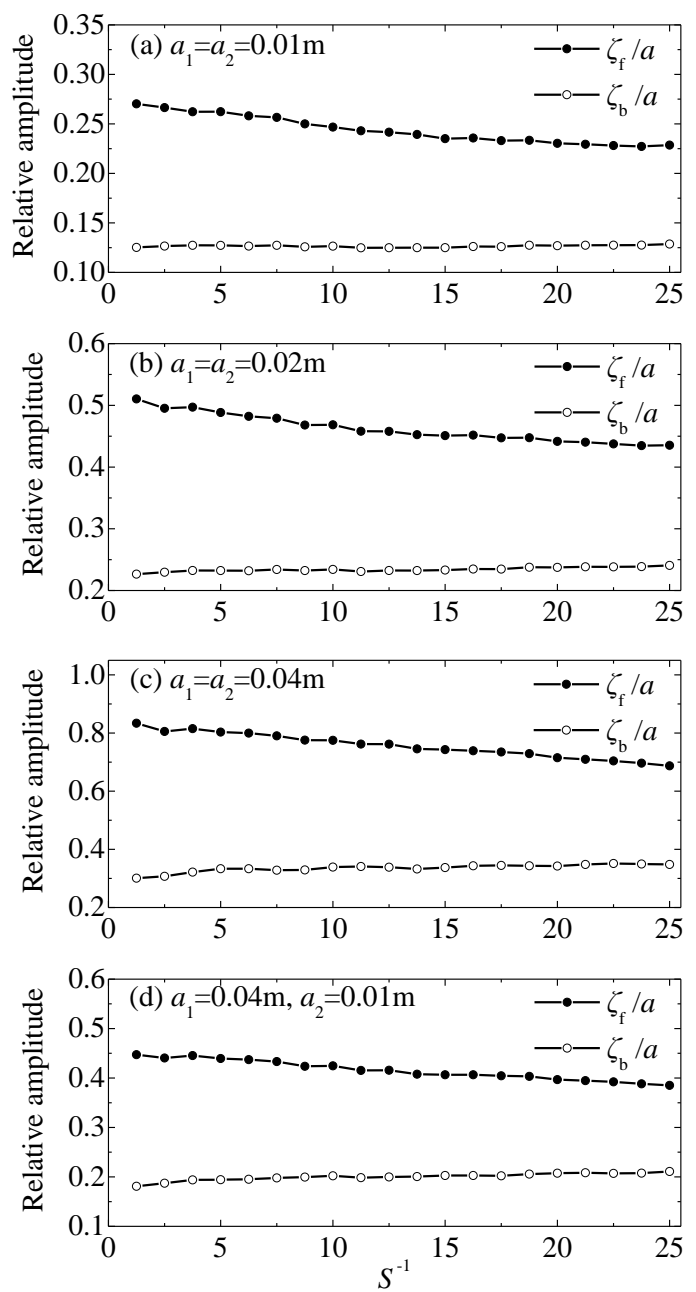

With ridge
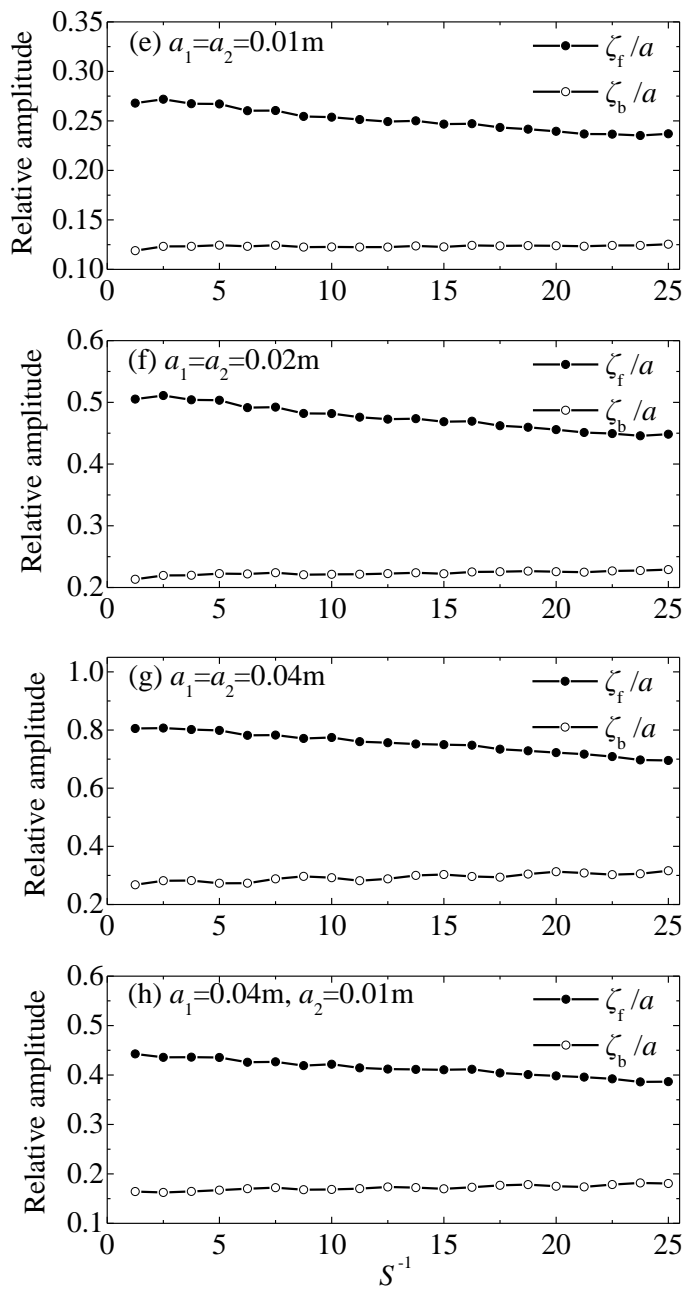

Fig. 10. Variations of the separating amplitudes of the bound and free IG waves with respect to the slope coefficient, $S^{-1}$, under the conditions of different incident primary wave amplitudes. (a)-(d) correspond to the cases without the ridge, and (e)-(h) correspond to the cases with the ridge.

(a) Without ridge

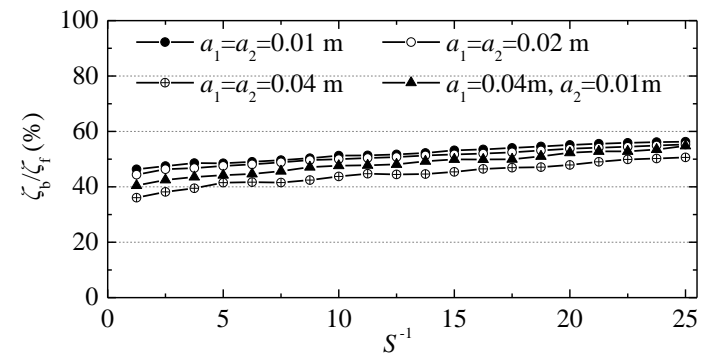

(b) With ridge

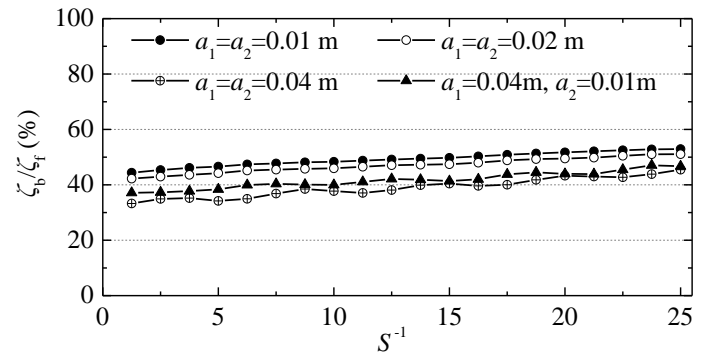

Fig. 11. The amplitude ratios, $\zeta_{\mathrm{b}} / \zeta_{\mathrm{f}}$, for all the cases with different plane reef-face slopes. (a) and (b) correspond to the cases without and with the reef ridge, respectively. 

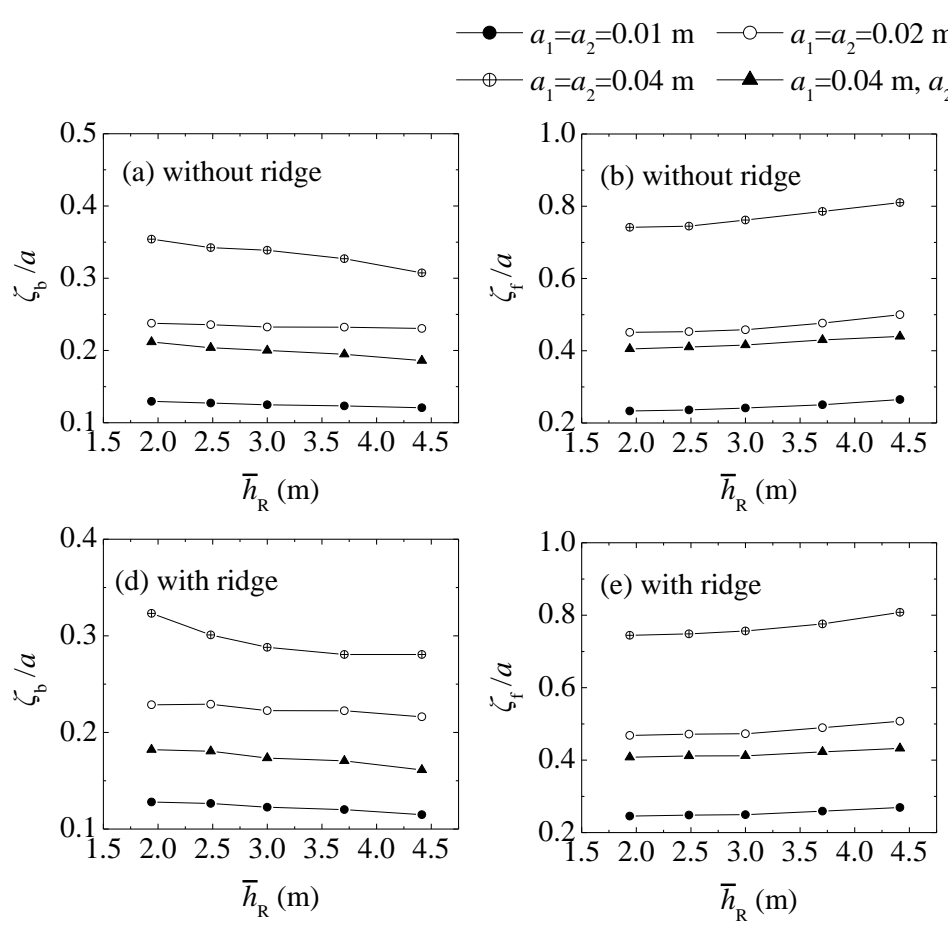

Fig. 12. Variations of the separating amplitudes of the bound and free IG standing waves and their relative components with respect to the mean water depth over the reef face with the width of $b=50 \mathrm{~m}$. (a)-(c) correspond to the cases without the ridge, and (d)-(f) correspond to the cases with the ridge.

To investigate influences of various bottom profiles over the reef face on the bound and free IG wave components inside the harbor, five different topographies, as shown in Fig. 5, under the conditions of $b=50 \mathrm{~m}$ and $100 \mathrm{~m}$ are considered. Fig. 12 demonstrates the variations of the separating amplitudes of the bound and free IG standing waves and their relative components with respect to the mean water depth over the reef face, $\bar{h}_{\mathrm{R}}$, under the conditions of $b=50 \mathrm{~m}$. It is shown that, regardless of the incident primary wave amplitudes, the modulation rates of the wave groups and whether the reef ridge exists or not, the amplitude of the free IG waves always increases monotonically with the increasing of the mean water depth over the reef face, $\bar{h}_{\mathrm{R}}$. However, for the amplitude of the bound IG waves and the amplitude ratio, $\zeta_{b} / \zeta_{\text {f }}$, both of them monotonically decrease with the increasing of $\bar{h}_{\mathrm{R}}$. Fig. 13 illustrates the variations of the 
amplitudes of the bound and free IG standing waves and their relative components with respect to $\bar{h}_{\mathrm{R}}$ under the condition of $b=100 \mathrm{~m}$. Just like that in the case of $b=50 \mathrm{~m}$, the amplitude of the bound IG waves also decreases gradually with the increasing of $\bar{h}_{\mathrm{R}}$. However, the changing trends of the amplitude of the free IG waves and the amplitude ratio, $\zeta_{\mathrm{b}} / \zeta_{\mathrm{f}}$, are significantly different from those shown in Fig. 12, and both of them do not monotonically change with respect to $\bar{h}_{\mathrm{R}}$. Specifically speaking, the amplitude of the free IG waves decreases first and then increases with $\bar{h}_{\mathrm{R}}$, and the amplitude ratio, $\zeta_{\mathrm{b}} / \zeta_{\mathrm{f}}$, increases first and then decreases with $\bar{h}_{\mathrm{R}}$, which indicates that both the amplitude of the free IG waves and the amplitude ratio inside the harbor depends on both the mean water depth and the bottom profile over the reef face under the condition of $b=100 \mathrm{~m}$.

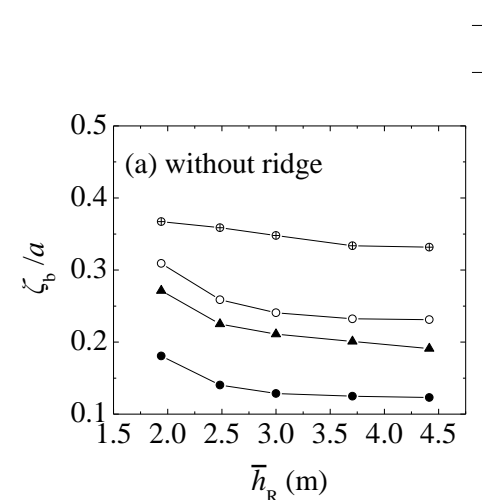

$$
\begin{aligned}
& \longrightarrow a_{1}=a_{2}=0.01 \mathrm{~m} \longrightarrow a_{1}=a_{2}=0.02 \mathrm{~m} \\
& \multimap a_{1}=a_{2}=0.04 \mathrm{~m} \longrightarrow a_{1}=0.04 \mathrm{~m}, a_{2}=0.01 \mathrm{~m}
\end{aligned}
$$
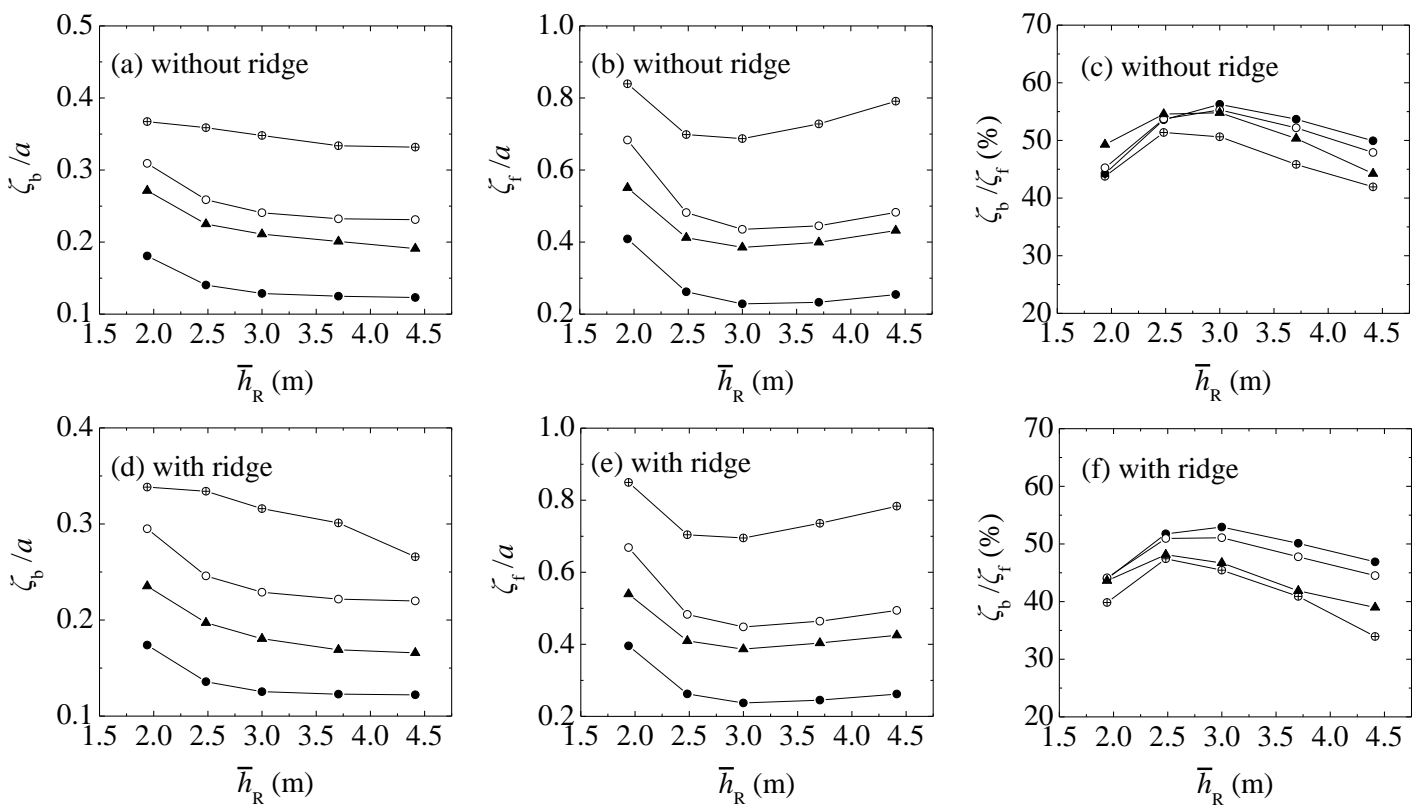

Fig. 13. Variations of the separating amplitudes of the bound and free IG standing waves and their relative components with respect to the mean water depth over the reef face with the width of $b=100 \mathrm{~m}$. (a)-(c) correspond to the cases without the ridge, and (d)-(f) correspond to the cases with the ridge. 

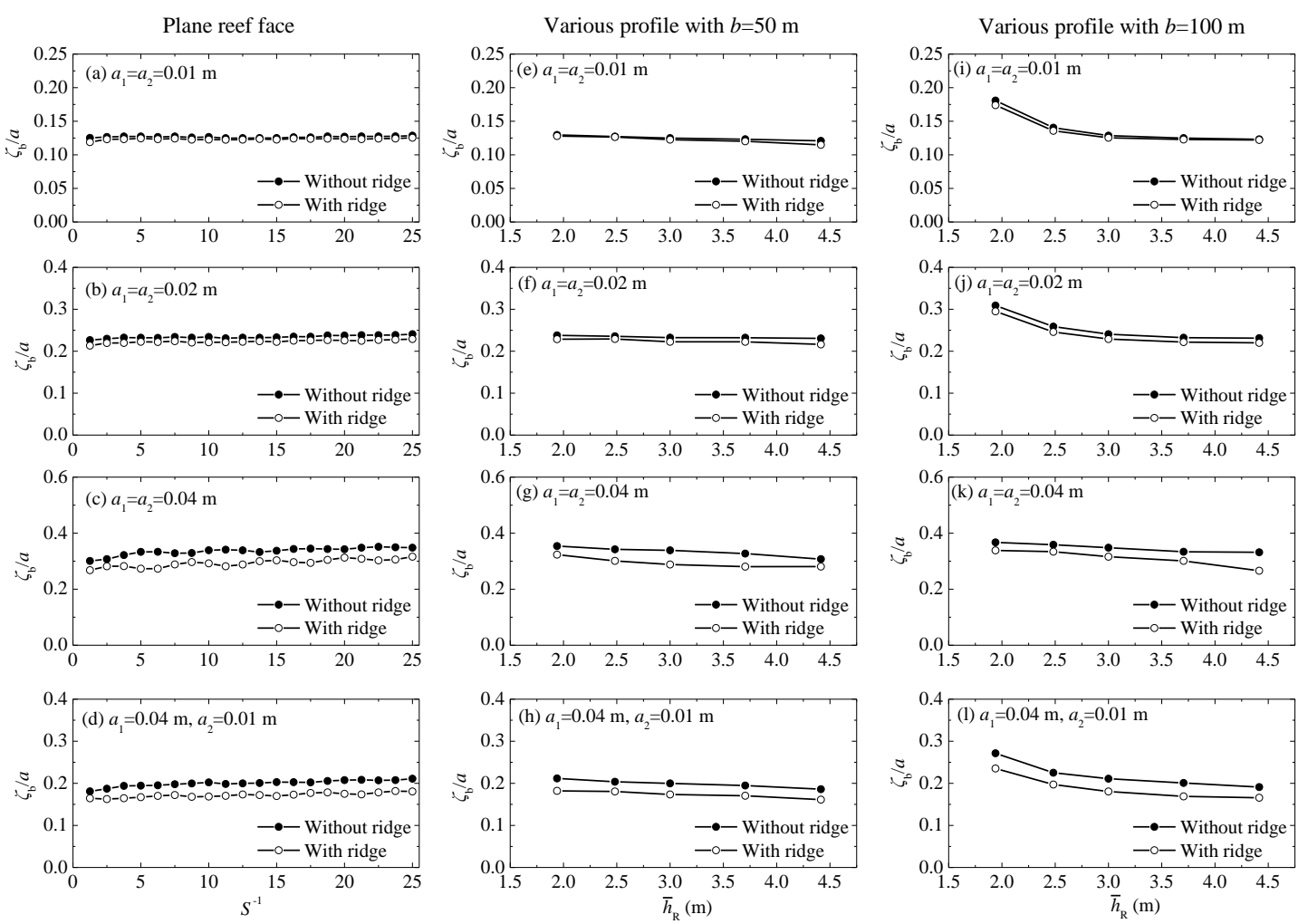

Fig. 14. Comparison of the amplitudes of the bound IG waves under the two conditions of the existence of the reef ridge and no reef ridge. (a)-(d) correspond to the cases with plane reef faces; (e)-(h) and (i)-(l) correspond to the cases with various reef-face profiles under the conditions of $b=50 \mathrm{~m}$ and $100 \mathrm{~m}$, respectively.

Fig. 14 demonstrates the comparison of the amplitudes of the bound IG waves under the two conditions of the existence of the reef ridge and no reef ridge. It can be seen that when the harbor is subjected to the incident primary waves with the smallest amplitudes, i.e. $a_{1}=a_{2}=0.01 \mathrm{~m}$, the idealized reef ridge used in this paper has negligible influence on the bound IG waves inside the harbor (see Fig. 14a, e and i). However, as the incident primary wave amplitudes increase, the existence of the reef ridge gradually restrains the bound IG waves inside the harbor (refer to Fig. 14c, g and k), which may be due to that the reef ridge can significantly impede the propagation of the incident primary waves into the reef flat and the harbor for the large incident wave amplitudes, which leads to a weaker bound IG wave component based on its generation mechanism $[35,36]$. In addition, comparing Fig. 14b, f and $\mathrm{j}$ with Fig. 14d, $\mathrm{h}$ and $\mathrm{l}$ can find that 
for the same average incident primary wave amplitude, the degree of depression of the bound IG waves inside the harbor are also affected by the modulation rate of the wave groups, that is, a lower modulation rate of the wave groups leads to a higher degree of depression of the bound IG waves. Similar to Fig. 14, Fig. 15 shows the comparison of the amplitudes of the free IG waves under the two conditions of the existence of the reef ridge and no reef ridge. It is clearly seen that for all the incident primary wave amplitudes and the modulation rates of the wave groups considered in this paper, the existence of the reef ridge has little influence on the free IG waves inside the harbor.
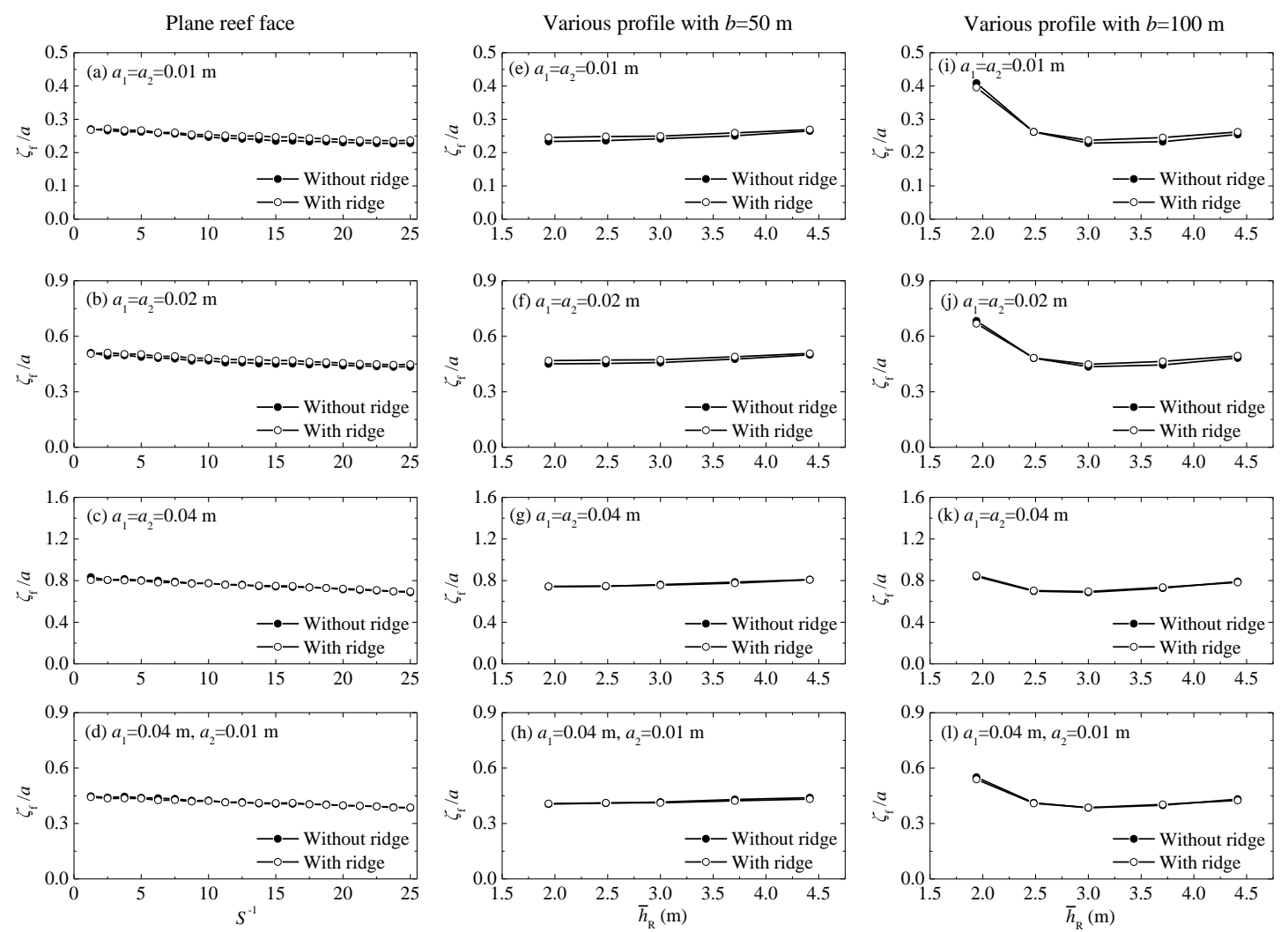

Fig. 15. Comparison of the amplitudes of the free IG waves under the two conditions of the existence of the reef ridge and no reef ridge. (a)-(d) correspond to the cases with plane reef faces; (e)-(h) and (i)-(l) correspond to the cases with various reef-face profiles under the conditions of $b=50 \mathrm{~m}$ and $100 \mathrm{~m}$, respectively.

\section{Conclusions}

The IG period oscillations inside an elongated harbor near the offshore fringing reef induced 
by bichromatic primary waves with slightly different frequencies are simulated using the FUNWAVE 2.0 model. The IG wave separation procedure proposed by Dong et al. [11] is used to decompose the IG period components inside the harbor into bound and free IG waves. Influences of the plane reef-face slope, the reef-face profile shapes and the existence of the reef ridge on the bound and free IG waves and their relative components inside the harbor are investigated systematically. The results of this study will improve the understanding of the effects of offshore fringing reefs on the IG period oscillations inside the harbor induced by the short wave groups.

The following conclusions can be drawn from the results of the present study:

1. For all the four incident primary wave amplitudes considered in this paper, the reef-face slope has a remarkable effect on the free IG waves inside the harbor; the latter increases gradually with the former. However, the bound IG waves inside the harbor seem insensitive to the variation of the reef-face slope. Accordingly, the amplitude ratio, $\zeta_{\mathrm{b}} / \zeta_{\mathrm{f}}$, always decreases with the increasing of the reef-face slope, regardless of the incident primary wave amplitudes, the modulation rates of the wave groups and whether the reef ridge exists or not.

2. The influences of the profile shapes on the IG period waves inside the harbor are closely related to the width of the reef face, $b$. The bound IG waves always decrease with the mean water depth over the reef face for both the two reef-face widths of $b=50 \mathrm{~m}$ and $100 \mathrm{~m}$. For the free IG waves, their amplitudes increase monotonically with the mean water depth for $b=50 \mathrm{~m}$; while for $b=100 \mathrm{~m}$, their amplitudes decrease first and then increase with the mean water depth. Accordingly, the amplitude ratio, $\zeta_{\mathrm{b}} / \zeta_{\mathrm{f}}$, decreases monotonically with the mean water depth for $b=50 \mathrm{~m}$; while for $b=100 \mathrm{~m}$, it increases first and then decreases with the mean water depth.

3. The existence of the reef ridge can restrain the bound IG waves inside the harbor to some extent when the incident primary wave amplitudes are relatively large, while the reef ridge has little influence on the free IG waves inside the harbor.

Finally, we reaffirm here that these conclusions are only valid for the given harbor and reef ridge, the ranges of the reef-face slopes and the profile shape variations studied in this paper. Wave breaking over fringing reefs may markedly change the distribution and strength of the IG period component inside the harbor, and the further study which takes into account the effect of wave 
breaking will be implemented in the near future.

\section{Acknowledgments}

This work was financially supported by the National Natural Science Foundation of China (Grant nos. 51609108, 51309124 and 51679113), the Natural Science Foundation of the Jiangsu Higher Education Institutions of China (Grant no. 16KJB570004), the State Key Laboratory of Coastal and Offshore Engineering at Dalian University of Technology (Grant no. LP1602), the Jiangsu Key Laboratory of Coast Ocean Resources Development and Environment Security at Hohai University (Grant no. JSCE201508) and the Jiangsu Key Laboratory of Advanced Design and Manufacturing Technology for Ship at Jiangsu University of Science and Technology (Grant no. CJ1504).

\section{References}

[1] Bowers EC. Harbour resonance due to set-down beneath wave groups. Journal of Fluid Mechanics. 1977; 79: 71-92.

[2] Mei CC, Agnon Y. Long-period oscillations in a harbour induced by incident short waves. Journal of Fluid Mechanics. 1989; 208: 595-608.

[3] Wu JK, Liu PL-F. Harbour excitations by incident wave groups. Journal of Fluid Mechanics. 1990; 217: 595-613.

[4] López M, Iglesias G. Long wave effects on a vessel at berth. Applied Ocean Research. 2014; 47: $63-72$.

[5] De Jong MPC, Battjes JA. Seiche characteristics of Rotterdam Harbour Coastal Engineering. 2004; 51: 373-386

[6] Fabrikant AL. Harbor oscillations generated by shear flow. Journal of Fluid Mechanics. 1995; 282: 203-217.

[7] Kulikov EA, Rabinovich AB, Thomson RE, Bornhold BD. The landslide tsunami of November 3, 1994, Skagway Harbor, Alaska. Journal of Geophysical Research. 1996; 101: 6609-6615.

[8] Pattiaratchi CB, Wijeratne EMS. Tide gauge observations of 2004-2007 Indian Ocean tsunamis from Sri Lanka and Western Australia. Pure and Applied Geophysics. 2009; 166: 
[9] Vanoni VA, Carr JH. Harbor surging. Proceedings of the 1st International Conference on Coastal Engineering. Long Beach1950. p. 60-68.

[10] Girolamo PD. An experiment on harbour resonance induced by incident regular waves and irregular short waves. Coastal Engineering. 1996; 27: 47-66.

[11] Dong G, Gao J, Ma X, Wang G, Ma Y. Numerical study of low-frequency waves during harbor resonance. Ocean Engineering. 2013; 68: 38-46.

[12] Gao J, Ji C, Gaidai O, Liu Y. Numerical study of infragravity waves amplification during harbor resonance. Ocean Engineering. 2016; 116: 90-100.

[13] Marcos M, Monserrat S, Medina R, Lomonaco P. Response of a harbor with two connected basins to incoming long waves. Applied Ocean Research. 2005; 27: 209-215.

[14] Liu PL-F. Effects of depth discontinuity on harbor oscillations. Coastal Engineering. 1986; 10: $395-404$.

[15] Panchang V, Chen W, Xu B, Schlenker K, Demirbilek Z, Okihiro M. Exterior bathymetric effects in elliptic harbor wave models. Journal of Waterway, Port, Coastal and Ocean Engineering. 2000; 126: 71-78.

[16] Gao J, Ma X, Dong G, Wang G, Ma Y. Numerical study of transient harbor resonance 602 induced by solitary waves. Proceedings of the Institution of Mechanical Engineers, Part M: Journal of Engineering for the Maritime Environment. 2016; 230: 163-176.

[17] Wang G, Zheng J, Liang Q, Zheng Y. Analytical solutions for oscillations in a harbor with a hyperbolic-cosine squared bottom. Ocean Engineering. 2014; 83: 16-23.

[18] Wang G, Zheng J, Liang Q, Zhang W, Huang C. Theoretical analysis of harbor resonance in harbor with an exponential bottom profile. China Ocean Engineering. 2015; 29: 821-834.

[19] Dongeren AV, Lowe R, Pomeroy A, Trang DM, Roelvink D, Symonds G, et al. Numerical modeling of low-frequency wave dynamics over a fringing coral reef. Coastal Engineering. 2013; 73: 178-190.

[20] Nwogu O, Demirbilek Z. Infragravity wave motions and runup over shallow fringing reefs. Journal of Waterway, Port, Coastal, and Ocean Engineering. 2010; 136: 295-305.

[21] Thotagamuwage DT, Pattiaratchi CB. Influence of offshore topography on infragravity period oscillations in Two Rocks Marina, Western Australia. Coastal Engineering. 2014; 91 : 
[22] Yao Y, Huang Z, Monismith SG, Lo EYM. 1DH Boussinesq modeling of wave transformation over fringing reefs. Ocean Engineering. 2012; 47: 30-42.

[23] Kirby JT, Long W, Shi F. Funwave 2.0 Fully Nonlinear Boussinesq Wave Model On Curvilinear Coordinates. Newark: Center for Applied Coastal Research, Dept. of Civil \& Environmental Engineering, University of Delaware; 2003.

[24] Hardy TA, Young IR. Field study of wave attenuation on an offshore coral reef. Journal of Geophysical Research. 1996; 101: 14311-14326.

[26] Chawla A, Kirby JT. A source function method for generation of waves on currents in Boussinesq models Applied Ocean Research. 2000; 22: 75-83.

[27] Bruno D, Serio FD, Mossa M. The FUNWAVE model application and its validation using laboratory data. Coastal Engineering. 2009; 56: 773-787.

[28] Gao J, Ji C, Liu Y, Gaidai O, Ma X, Liu Z. Numerical study on transient harbor oscillations induced by solitary waves. Ocean Engineering 2016; 126: 467-480.

[29] Rogers SR, Mei CC. Nonlinear resonant excitation of a long and narrow bay. Journal of Fluid Mechanics. 1978; 88: 161-180.

[30] Booij N. A note on the accuracy of the mild-slope equation. Coastal Engineering. 1983; 7 : 191-203.

[31] Suh KD, Lee C, Park WS. Time-dependent equations for wave propagation on rapidly varying topography. Coastal Engineering. 1997; 32: 91-117.

[32] Madsen PA, Fuhrman DR, Wang B. A Boussinesq-type method for fully nonlinear waves interacting with a rapidly varying bathymetry. Coastal Engineering. 2006; 53: 487-504.

[33] Ruessink BG. Bound and free infragravity waves in the nearshore zone under breaking and nonbreaking conditions. Journal of Geophysical Research. 1998; 103: 12795-12805.

[34] Mei CC. The Applied Dynamics of Ocean Surface Waves. New York: Wiley; 1983.

[35] Longuet-Higgins MS, Stewart RW. Radiation stress and mass transport in gravity waves, with application to 'surf beat'. Journal of Fluid Mechanics. 1962; 13: 481-504

[36] Longuet-Higgins MS, Stewart RW. Radiation stresses in water waves ; a physical discussion, with applications. Deep-Sea Research. 1964; 11: 529-562. 